\title{
Surface Modification of Aluminium Alloys with Laser Shock Processing
}

\author{
Uroš Trdan ${ }^{1}$ - José Luis Ocaña ${ }^{2}$ - Janez Grum ${ }^{1, *}$ \\ ${ }^{1}$ University of Ljubljana, Faculty of Mechanical Engineering, Slovenia \\ ${ }^{2}$ Centro Láser U.P.M., Universidad Politécnica de Madrid, Spain
}

An adequate residual stress variation and frequently also improved corrosion resistance of a material are key requirements for usability of numerous machine components in various applications. The aim of the investigation conducted was to determine optimum Laser Shock Processing (LSP) parameters for aluminium specimens in order to obtain the desired residual stress variation and improved corrosion resistance. LSP treatment was performed with a Q-switched Nd:YAG laser with a wavelength of 1064 $\mathrm{nm}$. In order to statistically confirm the optimum process parameters, a factorial design was applied, in which the first experimental factor was pulse density, i.e. 900 and 2500 pulses $/ \mathrm{cm}^{2}$, the second factor was the type of material used, i.e. aluminium alloys AlMgSiPb and AlSilMgMn and the third factor was the direction of LSP surface sweep, i.e. longitudinal and transversal direction.

The experiments made confirmed a characteristic influence of the first factor representing different pulse densities. An analysis of residual stresses confirmed that in processing with 2500 pulses $/ \mathrm{cm}^{2}$ the highest compressive residual stresses were obtained. Potentiodynamic corrosion testing confirmed that the higher pulse density resulted in a stronger shift of pitting potential, which provided higher corrosion resistance.

(C)2011 Journal of Mechanical Engineering. All rights reserved.

Keywords: Laser Shock Processing, surface roughness, residual stresses, microhardness, pitting corrosion, analysis of variance

\section{INTRODUCTION}

Laser Shock Processing (LSP) is an innovative surface treatment, with which mostly a Q-switched Nd:YAG laser with short pulses of several ns and with a power density, in the pulse peak, of as much as several tens of GW/ $\mathrm{cm}^{2}$ is used. In contrast to conventional Shot Peening (SP), which provides kinetic energy of hard particles [1] and [2], LSP is based on plasma generation at the moment of the interaction of laser light with a workpiece material, which produces shock impact waves and elasto-plastic shifts of atomic planes in the material [3] and [4].

Due to the shock waves generated, the dislocation density considerably increases. Consequently, fatigue resistance also notably increases.

Zhang and Yao [5] applied LSP to different types of steels, aluminium alloys, and titanium alloys. LSP produces shocks of motive quantity, which produce considerable densification of dislocations and generation of compressive residual stresses of high gradient [4]. In practice, technologists and engineers frequently require the introduction of compressive residual stresses since it improves the fatigue resistance of a material [6] and [7].

Commercially available laser sources and major advancement of laser engineering have permitted various industrial applications of LSP. LSP is frequently applied to exacting components, particularly in the aircraft industry for treatment of the most demanding components such as turbine spades of an aircraft F-16 Falcon and a bombardier F-22 Rockwell [8].

In numerous studies Sano et al. [9] confirmed the applicability of LSP, particularly because of improved material resistance to stresscorrosion cracking (SCC). LSP was carried out at specimens made of stainless steel SUS304 having a size of $10 \times 50 \times 2 \mathrm{~mm}$, pulse duration being $8 \mathrm{~ns}$ and a degree of overlapping of 7000 pulses $/ \mathrm{cm}^{2}$. Corrosion tests carried out in a vapour chamber for 500 hours confirmed an influence of LSP on increased material resistance to SCC.

*Corr. Author's Address: University of Ljubljana, Faculty of Mechanical Engineering, 
The same specimens were also used to perform a microscopic analysis, which confirmed the presence of cracks in the specimens in the asdelivered state whereas in the LSP-treated specimens no cracks were found.

Hong and Chengye [10] studied the effects of individual LSP parameters such as laser-beam power density, laser-spot size, pulse duration, and pulse density, i.e. degree of overlapping.

It was found that a correct choice of the processing parameters provided desired variations of hardness and residual stresses in the surface of machine components which, in turn, provided improved material fatigue resistance.

\section{EXPERIMENTAL}

The aim of the investigation conducted was an analysis of the influence of pulse density per area unit of LSP of two types of aluminium alloys with reference to the surface profile and roughness obtained, and variations of residual stresses and microhardness. Furthermore, an analysis of a change of corrosion resistance with potentiodynamic corrosion testing and confirmation of an improved surface condition on SEM followed.

In order to determine the optimum LSP parameters, a statistical evaluation of experimental data with the factorial design was chosen. The factorial design is particularly useful when an influence of at least two factors to an output response of the experimental process is treated [11]. Grum and Slabe [12] confirmed the factorial design as a suitable method for a rapid choice of optimum heat-treatment conditions with lasersurfaced specimens.

\subsection{Experiment and Factorial Design}

Fig. 1 shows a block diagram of the experimental process and the responses concerned. The comprehensive analysis of the specimens is to provide the most favourable surface integrity condition.

An evaluation of the LSP parameters chosen was performed with following response characteristics:

- Specimen surface profile prior to and after processing expressed by an average arithmetic surface roughness - $R_{a}$.

- A profile of minimal principal residual stresses $\left(\sigma_{\min }^{r s}\right)$ in the thin surface layer determined by the hole drilling relaxation method

- Microhardness variation in the thin surface layer of the specimen material $-H V 0.2$.

- Corrosion resistance expressed by a pitting potential and a number of pits formed at the material surface.

\subsection{Material Selection}

For a comparison of the effect of shock waves after LSP two aluminium alloys, i.e. $\mathrm{AlMgSiPb}$ and $\mathrm{AlSi} 1 \mathrm{MgMn}$, were chosen. Alloys were in the precipitation-hardened state $\mathrm{T}-651$. The alloys were subjected to preliminary homogenization at a temperature of $540{ }^{\circ} \mathrm{C}$, then quenched to ambient temperature, subjected to tensile loading with a $2 \%$ strain, and subjected to artificial ageing at a temperature $T$ of $160{ }^{\circ} \mathrm{C}$ for 10 hours.

The procedure chosen for the preparation of the alloy produces a large number of precipitates, i.e. intermetallic phases, which result in higher

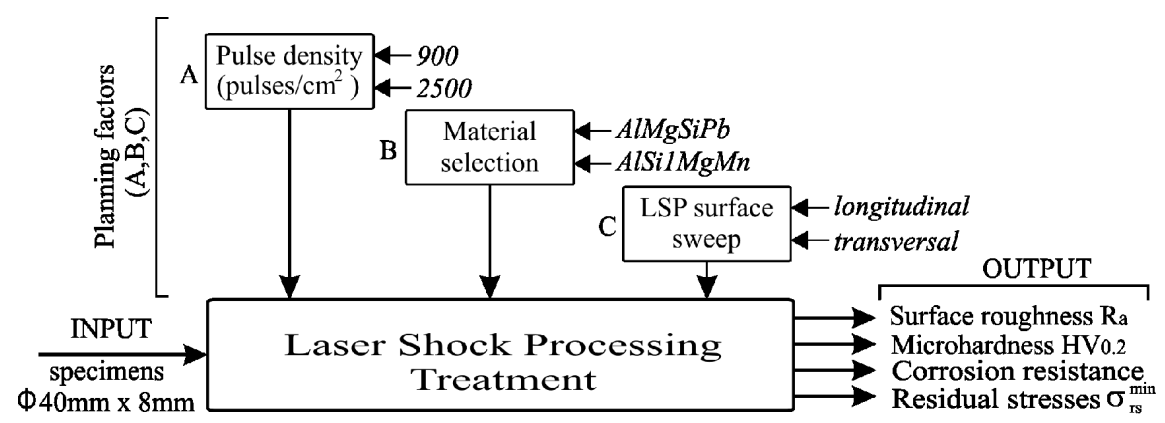

Fig. 1. Block diagram of experimental process 
Table 1. Chemical composition of the investigated alloys (wt \%)

\begin{tabular}{|c|c|c|c|c|c|c|c|c|c|c|}
\hline Alloy & $\mathrm{Mg}$ & $\mathrm{Si}$ & $\mathrm{Pb}$ & $\mathrm{Mn}$ & $\mathrm{Fe}$ & $\mathrm{Cr}$ & $\mathrm{Zn}$ & $\mathrm{Ti}$ & $\mathrm{Bi}$ & $\mathrm{Cu}$ \\
\hline AlMgSiPb & $0.6-1.2$ & $0.6-1.2$ & $0.4-2.0$ & $0.4-1.0$ & 0.5 & 0.3 & 0.3 & 0.2 & 0.7 & 0.1 \\
\hline AlSilMgMn & $0.6-1.2$ & $0.7-1.3$ & - & $0.4-1.0$ & 0.5 & 0.25 & 0.2 & 0.14 & - & 0.1 \\
\hline
\end{tabular}

material hardness and high ultimate tensile strength and yield stress $\left(R_{m}=350 \mathrm{MPa}, R_{p 0.2}=320 \mathrm{MPa}\right)$.

Chemical compositions of the alloys concerned are given in Table 1.

After the T-651 treatment $8 \mathrm{~mm}$ thick discshaped specimens were cut from a cylindrical drawn rod having a diameter of $40 \mathrm{~mm}$. In order to ensure the same initial state for all the specimens, cutting of the rod was carried out very carefully and under the same conditions.

An adequate specimen preparation thus prevented the surface overheating and a change of microstructure and mechanical properties. In this way specimens for LSP with initial residual stresses as small as possible were provided.

\subsection{Laser Shock Processing Setup}

LSP treatment of the specimens was performed in the Centro Láser U.P.M. Ctra deValencia, Madrid, Spain with a Q-switched $\mathrm{Nd}$ :YAG laser with a wavelength $\lambda$ of $1.064 \mu \mathrm{m}$ and a power density of $10.75 \mathrm{GW} / \mathrm{cm}^{2}$. Two levels of pulse density (900 and 2500 pulses $/ \mathrm{cm}^{2}$ ) were chosen, laser pulse duration $t_{p}$ of $10 \mathrm{~ns}$ being uniform with a repetition of $10 \mathrm{~Hz}$.

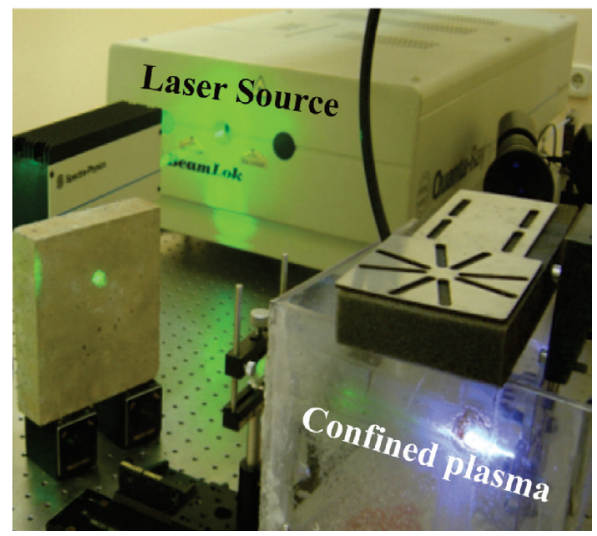

Fig. 2. Presentation of LSP experimental setup

Fig. 2 shows the presentation of LSP experimental setup, the specimen being clamped in a movable computer-aided $x-y$ table and submerged in water.

At the interaction of laser light with the material surface high-energy plasma will due to a high temperature generate at an extremely small surface area. Due to the confining medium, high pressure will occur at the specimen surface, which produces spreading of shock waves across the specimen.

The same state of treatment was provided under all processing conditions with a laserbeam sweep across the specimen surface. When processed with 900 pulses $/ \mathrm{cm}^{2}$, overlapping pitch among individual pulses equalled $0.33 \mathrm{~mm}$, and with 2500 pulses $/ \mathrm{cm}^{2} 0.22 \mathrm{~mm}$.

\section{RESULTS AND DISCUSSION}

\subsection{Surface Roughness Analysis}

Due to the preliminary preparation of the specimens with the cutter and LSP surface sweep direction, it was decided to establish surface profiles in the longitudinal (L) and transverse (T) directions, by average values of the mean arithmetic roughness $\overline{R_{a L}}$ and $\overline{R_{a T}}$ and by three profile measurements. For a comparison and analysis of specimen surface roughness, a measuring length $1 \mathrm{~m}$ of $8 \mathrm{~mm}$ was chosen. Measurements were made with a profile meter Surtronic 3+, product of Taylor/Hobson Pneumo, using a Gaussian filter, cut-off $0.8 \mathrm{~mm}$

Fig. 3 shows topographic images of the surface that confirm an extreme dependence of surface roughness on LSP conditions. The increase in surface roughness is a consequence of numerous laser-beam interactions with the specimen surface due to the overlapping of tracks and cumulative action of shock waves at the interaction point.

The roughness $R_{a}$ of the measured initial specimen, without laser peening amounts to $0.72 \mu \mathrm{m}$ in the $L$ direction and $0.81 \mu \mathrm{m}$ in the $T$ direction. At the specimen treated with 900 pulses/ $\mathrm{cm}^{2} R_{a}$ amounts to $3.74 \mu \mathrm{m}$ in $L$ direction and 6.0 
a)

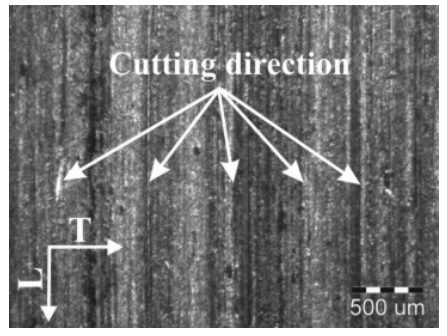

b)

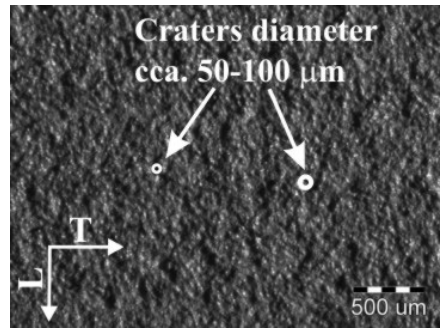

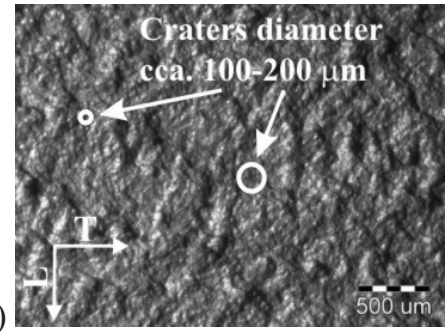

Fig 3. Topographic images and specimen surface profiles of alloy AlSilMgMn; a) initial state, without LSP, b) LSP with 900 pulses $/ \mathrm{cm}^{2}$ and c) LSP with 2500 pulses $/ \mathrm{cm}^{2}$

$\mu \mathrm{m}$ in $T$ direction. The highest roughness increase was noticed at the specimen, which was treated with 2500 pulses $/ \mathrm{cm}^{2}$, i.e. $\overline{R_{a L}}=5.36 \mu \mathrm{m}$ and $\overline{R_{a T}}$ $=9.11 \mu \mathrm{m}$.

From a comparison of the surface topographies it can be inferred that the specimen surfaces after LSP differ in crater sizes. With the higher pulse density, the size of the surface craters occurring ranges between 100 and 200 $\mu \mathrm{m}$ and is by factor 2 greater than with the lower pulse density, with which crater diameters range between $50 \mu \mathrm{m}$ and $100 \mu \mathrm{m}$.

The calculated values of the mean arithmetic surface roughness $R_{a}$ were verified also with an analysis of variance (Table 2). The analysis of variance confirmed that the pulse density and roughness profile measurement in the longitudinal (L) and transverse (T) directions exerted a significant influence on the surface condition after LSP. The influence of individual factors and their interactions is shown with a pie chart in Fig. 4. The influence of an individual factor is determined by:

$$
\text { Factor effect }=\frac{S S_{\text {factor }}}{S S_{\text {total }}-S S_{\text {error }}} \cdot 100[\%],
$$

where $S S_{\text {factor }}$ is the deviation square sum of the calculated factor $\left[\mu \mathrm{m}^{2}\right]$ and $S S_{\text {total }}$ is the total deviation square sum $\left[\mu \mathrm{m}^{2}\right]$.

From Fig. 4 it can be inferred that the greatest influence on the final surface roughness $R_{a}$ is exerted by pulse density, i.e. with an influence fraction of $76.23 \%$; then follows the direction of roughness measurement with an influence fraction of $8.96 \%$.

The smallest influence is exerted by the type of material, i.e. $1.51 \%$, which is a very low fraction of influence.

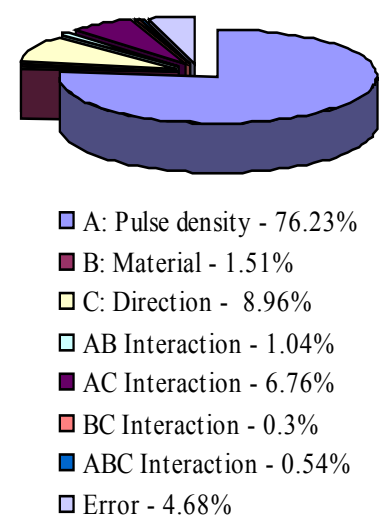

Fig. 4. Pie chart showing influence of factors

\subsection{Residual Stresses Analysis}

Knowledge of the residual-stress variation in the thin surface layer of a material gives an insight into material condition. In practice, instead of long-term material fatigue testing, measurement of residual stresses is preferred as high compressive residual stresses in the surface result in improved fatigue resistance of the material and better resistance to fatigue cracks.

Strain measurements and calculations of residual stresses in the surface layer were based on the relaxation hole-drilling method in accordance with the ASTM standard [13] and using measuring resistance rosettes CEA-06-062-UM and device RS-200 Milling Guide, Vishay Group.

Fig. 5 shows variations of the minimal principal residual stresses. From the residualstress variation it can be inferred that the values of the minimal compressive residual stresses $\left(\sigma_{\min }\right)$ in the specimens prior to LSP are ideal since they amount to around $0 \mathrm{MPa}$. 
Table 2. Results of the three-factor analysis of variance of mean arithmetic roughness $R a$

\begin{tabular}{|l|c|c|c|c|c|c|}
\hline Source of variation & $S S_{i}\left[\mu \mathrm{m}^{2}\right]$ & $v_{i}[/]$ & $M S_{i}\left[\mu \mathrm{m}^{2}\right]$ & $F_{0}[/]$ & $F_{v, 24,0.01}[/]$ & $P[/]$ \\
\hline Pulse density (A) & 229.557 & 2 & 114.778 & 195.628 & 9.34 & $<0.0001$ \\
\hline Material (B) & 4.551 & 1 & 4.551 & 7.757 & 14.03 & 0.0103 \\
\hline Direction (C) & 26.971 & 1 & 26.971 & 45.969 & 14.03 & $<0.0001$ \\
\hline Interaction AB & 3.119 & 2 & 1.560 & 2.658 & 9.34 & 0.0906 \\
\hline Interaction AC & 20.356 & 2 & 10.178 & 17.348 & 9.34 & $<0.0001$ \\
\hline Interaction BC & 0.890 & 1 & 0.890 & 1.517 & 14.03 & 0.23 \\
\hline Interaction ABC & 1.615 & 2 & 0.808 & 1.377 & 9.34 & 0.2716 \\
\hline Error & 14.081 & 24 & 0.587 & - & - & - \\
\hline Total & 301.140 & - & - & - & - & - \\
\hline
\end{tabular}
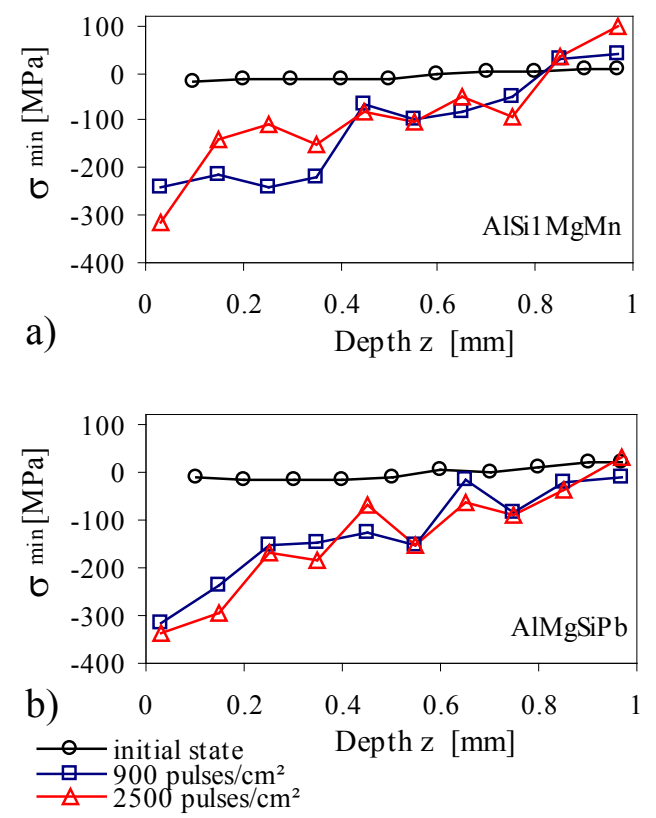

Fig. 5. Variation of minimal principal residual stresses $\left(\sigma_{\min }\right)$; a) AlSilMgMn, b) AlMgSiPb

Such a variation confirms that the heat treatment T-651 is adequate for the initial material state. In alloy $\mathrm{AlMgSiPb}$ residual stresses range between -10 and $+30 \mathrm{MPa}$ and in alloy AlSilMgMn between $\pm 20 \mathrm{MPa}$.

The analysis of the principal residual stresses after LSP treatment of the specimens with a power density of $10.75 \mathrm{GW} / \mathrm{cm}^{2}$ in alloy $\mathrm{AlMgSiPb}$ confirmed that the influence of pulse density is important. In this alloy with the pulse density of 900 pulses $/ \mathrm{cm}^{2}$ compressive residual stresses of $-314 \mathrm{MPa}$ are obtained in a depth of
$0.033 \mathrm{~mm}$ whereas with th pulse density of 2500 pulses $/ \mathrm{cm}^{2}$, they are a little higher, i.e. $-337 \mathrm{MPa}$.

A similar variation of the minimal principal residual stresses after LSP treatment can also be noted with aluminium alloy AlSilMgMn. In this case with 900 pulses $/ \mathrm{cm}^{2}$ the highest stresses obtained amount to $-242 \mathrm{MPa}$, and with 2500 pulses $/ \mathrm{cm}^{2}$ to as much as $-317 \mathrm{MPa}$.

\subsection{Microhardness Analysis}

The microhardness variations prior to and after LSP of aluminium alloys $\mathrm{AlMgSiPb}$ and AlSilMgMn were measured using the Vickers method with a load of $200 \mathrm{~g}\left(H V_{0.2}\right)$, as at least ten measurements are required to establish a suitable microhardness profile in the hardened layer and, consequently, a reliable microhardness variation.

Microhardness was measured with vertical and horizontal staggering between the two lines at a distance of a triple diagonal of an indentation between two adjacent indentations.

Fig. 6 shows through-depth microhardness variations in the hardened layer using different pulse densities. The microhardness variations are within the boundaries of expectation and confirm the LSP effects with regard to different pulse densities.

The highest microhardness value after LSP was measured at the specimen surface of alloy $\mathrm{AlMgSiPb}$ after treatment with 2500 pulses $/ \mathrm{cm}^{2}$. It amounted to $123 H V_{0.2}$.

After treatment with 900 pulses $/ \mathrm{cm}^{2}$ microhardness of $119 H V_{0.2}$ was achieved at the specimen surface of alloy AlMgSiPb. In comparison to the untreated material ( $\left.92 H V_{0.2}\right)$, the microhardness increased by as little as $12 \%$ whereas after treatment with 2500 pulses $/ \mathrm{cm}^{2}$ 

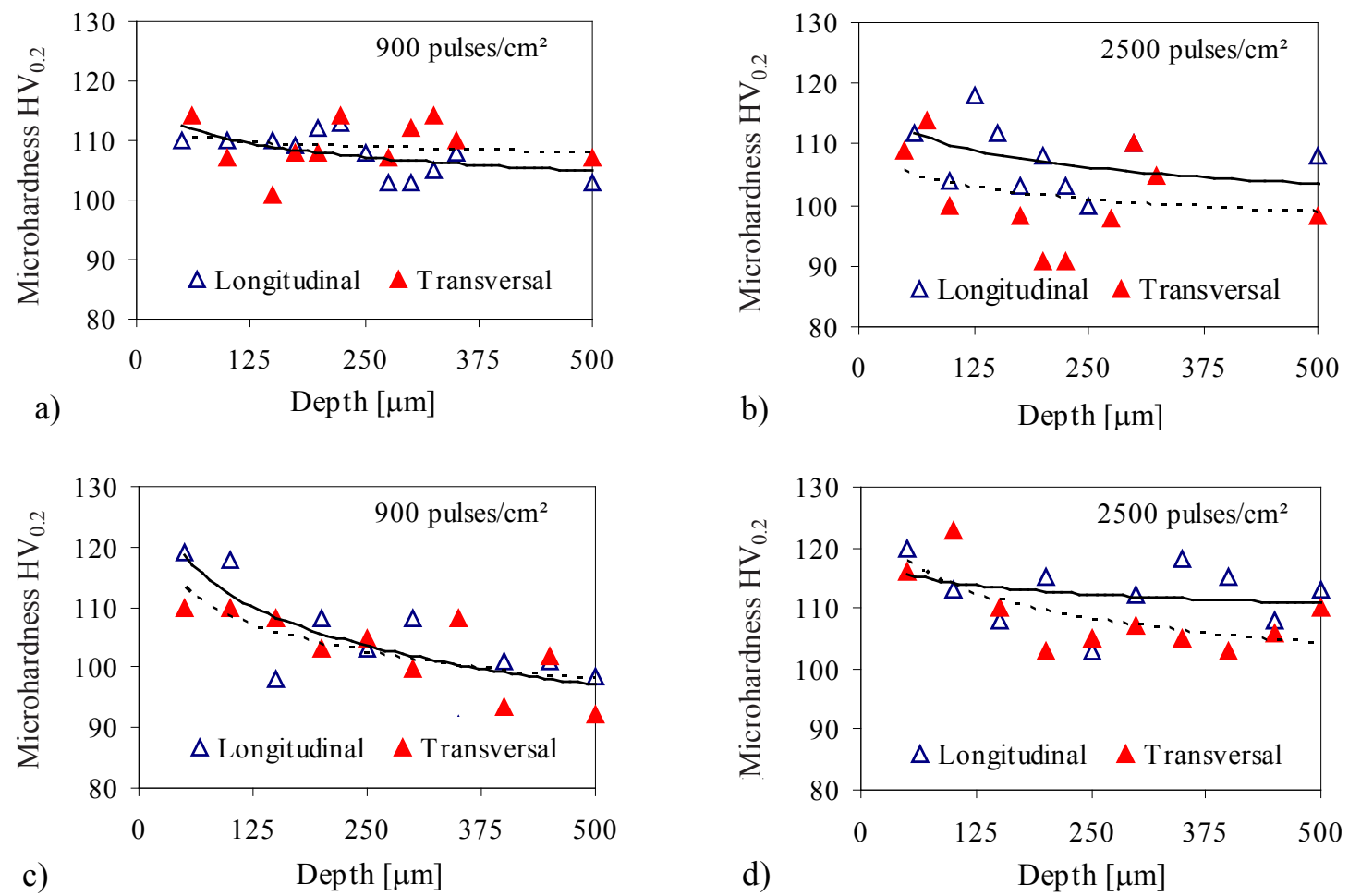

Fig. 6. Microhardness variation in thin surface layer; a) AlSilMgMn - 900 pulses/cm², b) AlSilMgMn$2500 \mathrm{pulses} / \mathrm{cm}^{2}$, c) AlMgSiPb - $900 \mathrm{pulses} / \mathrm{cm}^{2}$, d) AlMgSiPb - $2500 \mathrm{pulses} / \mathrm{cm}^{2}$

hardness increased by as much as $19.8 \%$. The same tendency of increasing microhardness at the surface was recorded in the same range also at the specimens of alloy AlSi1MgMn.

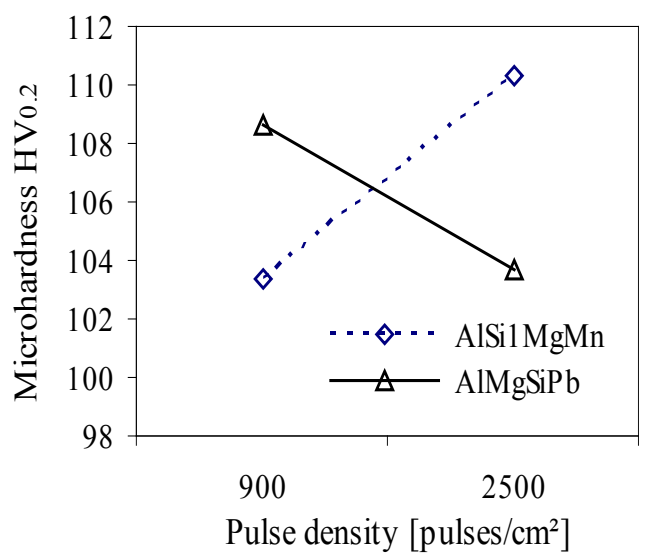

Fig. 7. Charcteristic influence of factors and interactions
The analysis of variance of the measured microhardness was used to verify the influence of pulse overlapping density and material. Fig. 7 shows characteristic influences of the factors of pulse density and material type on the average value of microhardness.

The results show obvious nonparallelism, i.e. a line intersection, which represents a strong interaction of the factors. The diagram additionally confirms the analysis of variance, which states a significant influence of the interaction of factors AB.

\subsection{Pitting Corrosion Analysis}

Aluminium alloys are frequently used in industrial applications due to their low density, and excellent corrosion resistance. In the presence of chloride ions the protective effect of a passive/ oxide film at the surface of aluminium alloys is drastically reduced, which results in serious corrosion damages in the form of small surface 


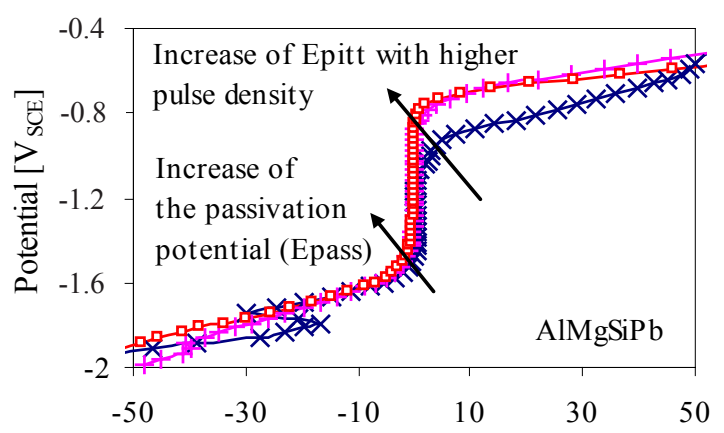

a)

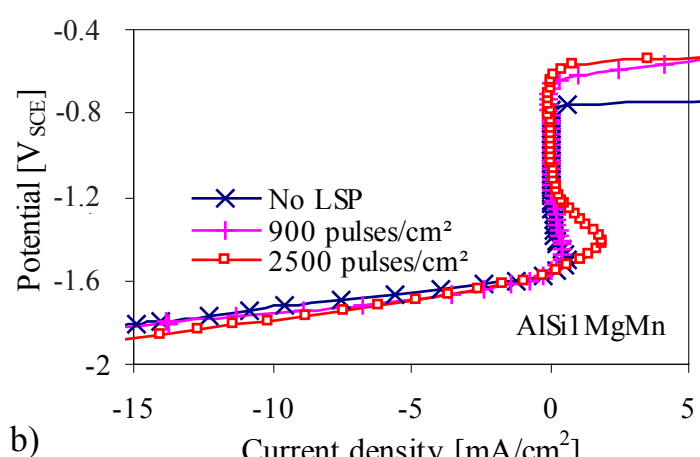

Fig. 8. Potentiodynamic polarization curves; a) AlMgSiP, b) AlSilMgMn
Table 3. Pitting potentials from electrochemical corrosion polarization tests

\begin{tabular}{cccc}
\hline Material & $\begin{array}{c}\text { Pulse density } \\
{\left[\mathrm{pulses} / \mathrm{cm}^{2}\right]}\end{array}$ & $\begin{array}{c}\mathrm{E}_{\text {pitt }} \\
{\left[\mathrm{mV}_{\mathrm{SCE}}\right]}\end{array}$ & $\begin{array}{c}\Delta \mathrm{E}_{\text {pitt }} \\
{\left[\mathrm{mV}_{\text {SCE }}\right]}\end{array}$ \\
\hline \multirow{3}{*}{ AlMgSiPb } & No LSP & -1166 & 0 \\
& 900 & -947 & +219 \\
& 2500 & -899 & +267 \\
\hline \multirow{3}{*}{ AlSi1MgMn } & No LSP & -782 & 0 \\
& 900 & -720 & +62 \\
& 2500 & -662 & +120 \\
\hline
\end{tabular}

pits. This type of corrosion is called pitting corrosion.

Corrosion resistance of the aluminium alloys was tested with potentiodynamic polarisation tests in a $3.5 \% \mathrm{NaCl}$ water solution. Anodic potentiodynamic polarisation tests were performed with Voltalab 21 potentiostat and corrosion cell CEC/TH, Radiometer Analytical.

The data were registered with a scan rate of potential of $10 \mathrm{mV} / \mathrm{s}$, with the potential range from -2000 to $-500 \mathrm{mV}_{\text {SCE. }}$.

From the variation of polarisation curves in Fig. 8 it can be inferred that with an increasing

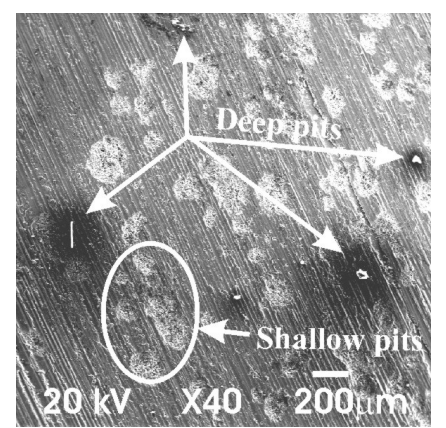

a1) No LSP

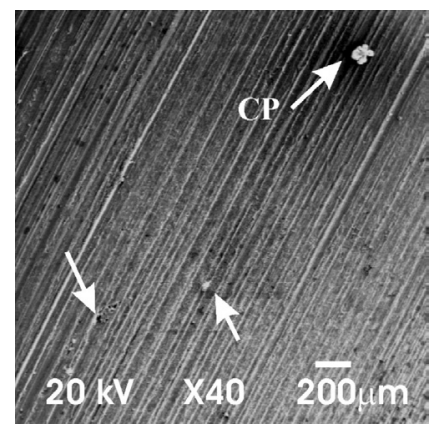

b1) No LSP

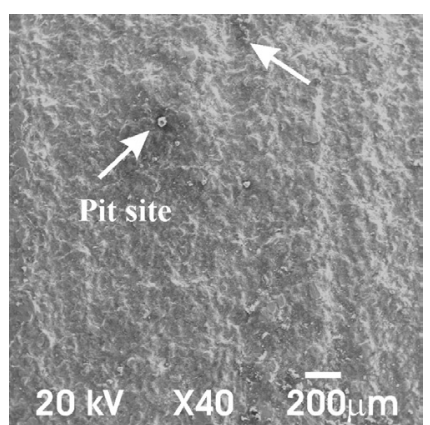

a2) 900 pulses $/ \mathrm{cm}^{2}$

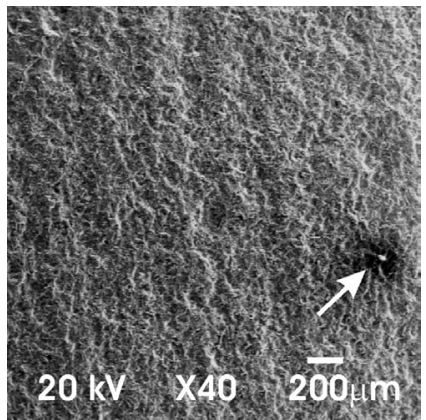

b2) $900 \mathrm{pulses} / \mathrm{cm}^{2}$

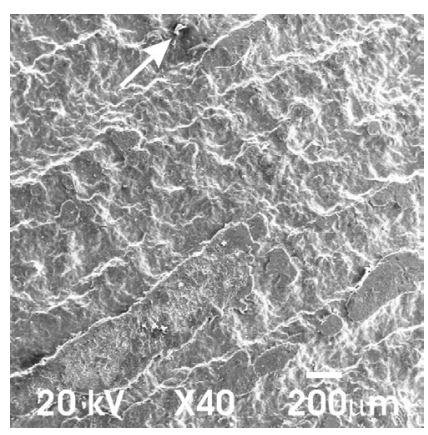

a3) 2500 pulses $/ \mathrm{cm}^{2}$

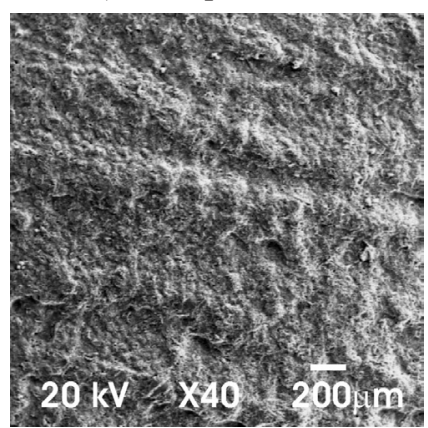

b3) 2500 pulses $/ \mathrm{cm}^{2}$

Fig. 9. SEM macrographs of the specimen surfaces; a) AlSilMgMn, b) AlMgSiPb 
laser-pulse density the passivation $\left(E_{\text {pass }}\right)$ and pitting potential $\left(E_{\text {pitt }}\right)$ will also increase.

Table 3 shows the results obtained in the potentiodynamic polarization tests of the specimens prior to and after LSP. Alloy AlMgSiPb treated with 900 pulses $/ \mathrm{cm}^{2}$ showed an increase in pitting potential of $219 \mathrm{mV}$ and after 2500 pulses/ $\mathrm{cm}^{2}$ an increase in the pitting potential of $267 \mathrm{mV}$ in comparison with the same material in the asdelivered state, was established.

An increase in pitting potential after LSP was noted also with alloy AlSi1MgMn.

For an additional confirmation of improved corrosion resistance, the specimens were verified also with the SEM microscope.

In accordance with an ASTM standard for the preparation of specimens after corrosion testing [14], the specimen surfaces were subjected to a preliminary cleaning action in nitric acid $\mathrm{HNO}_{3}$.

With all the specimens treated, the same cleaning time, i.e. 2 min, was used. Fig. 9 shows SEM images of the specimen surfaces prior to and after LSP with an additional corrosion test. From the surface images it can be assessed that with both aluminium alloys the largest number of corrosion damages (pits) at the specimen surfaces occurs in the as-delivered state. Whereas the surfaces of the specimens which were subjected to a preliminary LSP confirm that with a higher pulse density the number of pits will reduce. At the specimen surfaces after corrosion tests also a corrosion product $(\mathrm{CP})$ near pits, which mostly consists of $\mathrm{Al}(\mathrm{OH})_{3}$ is visible.

A metallographic analysis of the specimens after corrosion testing confirmed that alloy $\mathrm{AlMgSiPb}$ shows higher corrosion resistance since after corrosion testing there is a smaller number of pits than at alloy AlSi1MgMn.

\section{CONCLUSIONS}

The results obtained in the investigation permit the following conclusions:

The factorial design of the input parameters confirmed that aluminium alloy $\mathrm{AlMgSiPb}$ is a more suitable material with a smaller increase in surface roughness $R_{a}$ after LSP treatment with both pulse densities.
The analysis of residual stresses confirmed that after LSP treatment the specimens show higher compressive residual stresses with the higher pulse density. After treating alloy $\mathrm{AlMgSiPb}$ with $2500 \mathrm{pulses} / \mathrm{cm}^{2}$, compressive residual stresses of $-337 \mathrm{MPa}$ are obtained just beneath the surface in a depth of $0.033 \mathrm{~mm}$.

Corrosion testing confirmed that the intensity of pitting corrosion attack decreases with the increase in pulse density. With both alloys an increase in pitting potential with higher pulse density was confirmed.

The metallographic analysis of the specimens after corrosion testing confirmed alloy $\mathrm{AlMgSiPb}$ as better corrosion resistant material with a smaller number of pits than with aluminium alloy AlSilMgMn.

\section{REFERENCES}

[1] Zupanc U., Grum, J. (2011). Surface integrity of shot peened of 7075-T651 aluminium alloy. Strojniški vestnik - Journal of Mechanical Engineering, vol. 57, no. 5, p. 379-384.

[2] Žagar, S., Grum, J. (in press). Surface integrity after mechanical hardening of various aluminium alloys. Strojniški vestnik - Journal of Mechanical Engineering, DOI:10.5545/sv-jme.2010.092.

[3] Clauer, A.H. (1996). Surface performance of titanium. Gregory, J.K., Rack, H.J., Eylon, D. (eds.). The Metal Society of AIME, Warrendale, p. 217-230.

[4] Grum, J., Trdan, U., Hill, M.R. (2008). Laser shock processing of ENAW 6082 aluminium alloy surface. Materials Science Forum, vol. 589, p. 379-384.

[5] Zhang, W., Yao, Y.L. (2002). Micro scale laser shock processing of metallic components. Journal of Manufacuring Science and Engineering, vol. 124, p. 369-378.

[6] Hammersley, G., Hackel, L.A., Harris, F. (2000). Surface prestressing to improve fatigue strenght of components by laser shot peening. Optics and Lasers in Engineering, vol. 34, p. 327-337.

[7] Ocaña, J.L., Molpeceres, C., Porro, J.A., Gómez, G., Morales, M. (2004). Experimental assessment of the influence of irradiation parameters on surface deformation 
and residual stresses in laser shock processed metallic alloys. Appl. Surf. Sci., vol. 238, p. 501-505.

[8] Ding, K., Ye, L. (2006). Laser shock peening - Performance and process simulation. CRC Press, Woodhead Publishing Limited Cambridge.

[9] Sano, Y., Obata, M., Kubo, T., Mukai, N., Yoda, M., Masaki, K., Ochi, Y. (2006). Retardation of crack initiation and growth in austenitic stainless steels by laser peening without protective coating. Materials Science and Engineering A, vol. 417, p. 334-340.

[10]Hong, Z., Chengye, Y. (1998). Laser shock processing of 2024-T62 aluminum alloy. Materials Science and Engineering, A257, p. 322-327.
[11] Montgomery, D.C. (2001). Design and Analysis of Experiments. Wiley, New York.

[12] Grum, J., Slabe, J.M. (2004). The use of factorial design and response surface methodology for fast determination of optimal heat treatment conditions of different Ni-Co-Mo surfaced layers. Journal of Materials Processing Technology, vol. 155156, p. 2026-2032.

[13] ASTM Standard (1995). Standard Test Method for Determing Residual Stress by the Hole Drilling Relaxation method, ASTM E 837-01, ASTM Int., West Conshohocken.

[14] ASTM Standard (2003). Standard Practice for Preparing, Cleaning, and Evaluating Corrosion Test Specimens (G1-03), ASTM Int., West Conshohocken. 